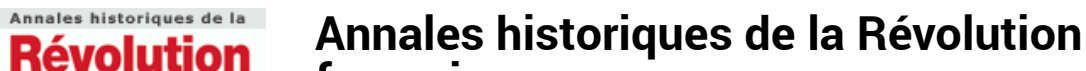

française française

333 | juillet-septembre 2003

Varia

\section{Bernard COTTRET, La Révolution américaine. La quête du bonheur (1763-1787)}

\section{Annie Duprat}

\section{(2) OpenEdition \\ Journals}

Édition électronique

URL : https://journals.openedition.org/ahrf/10814

DOI : 10.4000/ahrf.10814

ISSN : 1952-403X

Éditeur :

Armand Colin, Société des études robespierristes

Édition imprimée

Date de publication : 1 septembre 2003

ISSN : 0003-4436

Référence électronique

Annie Duprat, «Bernard cottret, La Révolution américaine. La quête du bonheur (1763-1787) », Annales historiques de la Révolution française [En ligne], 333 | juillet-septembre 2003, mis en ligne le 07 décembre 2009, consulté le 22 avril 2022. URL : http://journals.openedition.org/ahrf/10814 ; DOI : https://doi.org/10.4000/ahrf.10814

Ce document a été généré automatiquement le 22 avril 2022.

Tous droits réservés 


\title{
Bernard COTTRET, La Révolution américaine. La quête du bonheur (1763-1787)
}

\author{
Annie Duprat
}

\section{RÉFÉRENCE}

Bernard COTTRET, La Révolution américaine. La quête du bonheur (1763-1787), Paris, Perrin, 2003, 527 p., ISBN 2-262-01821-9, 24,5€.

1 Les premiers mots du chapitre introductif de cet ouvrage en énoncent d'emblée le projet: "C'est ici un livre sur le bonheur». Bernard Cottret, historien, spécialiste d'histoire religieuse et d'histoire des civilisations du monde anglo-saxon à l'époque moderne, place son étude dans le droit fil de l'enthousiasme des hommes des Lumières, dont l'espérance était de permettre l'avènement d'un monde nouveau, que ce soit dans le nouveau monde (l'Amérique) ou en Europe. Les liens qui ont uni les combattants de la liberté dans les treize colonies britanniques et, en France, tous ceux qui, eux aussi aspiraient à la liberté, sont bien connus ; mais étaient-ils si évidents ? Si l'affrontement entre les Français et les Anglais dans le contexte européen de la seconde moitié du XVIII siècle est assez facile à appréhender (rivalités commerciales sur le continent, en particulier avec les tribus indiennes, comme sur mer, avec les implantations coloniales des Antilles), pour comprendre l'écho de la guerre d'indépendance américaine de ce côté-ci de l'Atlantique il faut faire un long détour par le récit factuel de l'opposition des treize colonies au Parlement de Londres, la contestation fiscale, mais aussi opérer un retour sur la philosophie des Lumières, et ses origines bibliques ou antiques. Cependant, il faut bien remarquer que, si de nombreux chercheurs américains continuent à observer à la loupe, pour tenter de la comprendre, notre Révolution de 1789, la balance n'est pas du tout égale et peu de Français consacrent leurs travaux à ce 
sujet. Ce beau volume remplit donc une lacune de la bibliographie française, c'est pourquoi il mérite d'être tout particulièrement salué.

La lecture du livre peut se faire à deux niveaux : une lecture simple des 18 chapitres, présentés en trois parties (respectivement «la crise de l'empire, 1763-1773»; «le combat pour l'indépendance, 1774-1781»; "de la fédération à la constitution, 1781-1787 »). Cette première approche est facilitée par la qualité du style, très fluide, très direct et plein d'humour; on pourra aussi procéder à une lecture plus précise, et volontiers savante, dans les notes à la fois nombreuses et abondantes, qui occupent plus de 120 pages. Même pressé ou distrait, le lecteur se priverait de beaucoup d'informations et de sujets de réflexion s'il s'affranchissait de la lecture de ces notes qui, outre leur fonction habituelle d'appareil critique et de références de sources, reprennent et précisent des débats historiographiques (voir en particulier, sur les travaux de Palmer et le concept de "révolution atlantique ", les pages 122-123 et, sur l'évolution du concept lui-même entre la fin des années 50 et la fin des années 60 , la position d'Albert Soboul en note 8, p. 440 ; sur les transformations de l'acception du mot «révolution" en anglais depuis le XVII e siècle, voir la note 2, p.415). Les références bibliographiques, pour la plupart en anglais, et les sources, manuscrites ou imprimées, proviennent logiquement des trois origines de l'événement: l'Angleterre, l'Amérique et la France.

3 En introduction, et au fil des chapitres qui constituent les deux premières parties, l'auteur s'interroge donc sur ce qui unit les deux "républiques-sœurs", pour reprendre la formule de Patrice Higonnet, (Sister Republics, Cambridge, 1988), lui-même s'inscrivant dans la continuité de la pensée de Tocqueville; cependant, affirmer cela risquerait de réduire la part de la différence entre les deux histoires de deux entités (qui ne sont pas encore des "nations» au sens actuel du terme) que presque tout oppose à la fin du XVIII ${ }^{e}$ siècle. Les treize colonies britanniques, qui elles-mêmes peuvent être divisées en deux types, celles du Nord, protestantes, plus urbanisées, ayant développé une économie de fabrique, en un mot proches de la métropole anglaise, et celles du Sud, plus rurales, traversées d'influences catholiques, et dont l'économie se rapproche de celle de l'Europe féodale, n'offrent que peu de proximité avec une monarchie absolutiste et papiste. La survie du mouvement d'indépendance en Amérique passe donc par une attitude que Denis Lacorne (L'invention de la République. Le modèle américain, Paris, Hachette, 1991) a qualifié, par un anachronisme fructueux, de « realpolitik ». Mais, si cette perspective permet de bien comprendre l'enchaînement des faits et des alliances, en n'omettant pas le passé immédiat, celui de la guerre de Sept Ans qui avait vu la France mettre en place des alliances de revers avec les tribus indiennes, elle ne dispense pas d'une réflexion approfondie sur la supposée « exception » française (Révolution et République. L'exception française, Paris, Kimé, 1994); et, si la rupture avec l'Angleterre a aussi entraîné la fin du système monarchique pour les jeunes États-Unis, ce n'est certainement pas seulement au nom des idéaux de la Liberté, puisque, depuis 1688 au moins, les libertés fondamentales ont été placées à la base du système britannique (ce dont les gravures et les textes américains datant de ces années-là rendent grâce à la métropole). La réflexion change de sens, en Amérique comme en France, et passe, dans les deux pays, de l'étage aristocratique à l'étage démocratique, c'est-à-dire à la nécessité impérieuse de la prise en compte de l'intérêt général, de l'autonomie des habitants face à un pouvoir qui leur est extérieur. L'origine antiparlementaire du conflit américain ne rend pas seulement compte de l'opposition 
aux nouvelles mesures de taxation fiscale (en particulier le fameux "stamp act ») mais aussi d'une volonté affirmée d'appropriation de son destin, qui passe par une "américanisation" des esprits. Bernard Cottret nous précise la genèse de ce terme, apparu tout d'abord sous la forme du mot " américanisme ", sous la plume du révérend John Witherspoon, descendant du réformateur et polémiste écossais John Knox, au début des années 1780. En effet, l'un des éléments troublants de cette révolte antifiscale qui se mue en guerre d'indépendance réside dans la référence de plus en plus forte à l'altérité des colonies d'Amérique vis-à-vis de leur métropole; certes, lorsque les initiateurs de la partie de thé de Boston, en décembre 1773, se déguisent en Indiens pour attaquer les bateaux anglais et vider les sacs de thé dans le port de Boston, leurs costumes correspondent aux canons des allégories traditionnelles représentant ainsi l'Amérique. Mais, dans les textes pamphlétaires comme dans les journaux américains, l'idée qu'un peuple nouveau est en train de se constituer, en dehors des références européennes, est abondamment illustrée sous l'apparence de figures déjeunes Indiens.

4 "La Révolution est un tout ", affirme Bernard Cottret (p. 200) car, malgré la longueur, la complexité et les contradictions internes des processus à l'œuvre durant la guerre d'Indépendance, puis dans la recherche d'une Constitution (voir les réflexions tantôt théoriques, tantôt pragmatiques qui ont rempli la décennie 1781-1789, lorsque deux systèmes successifs ont été expérimentés, pp. 288-303), les Américains, comme juste après eux les Français, ont eu le sentiment de mener un combat placé sous les auspices de l'universalité. Or, pour justifier ce combat, pour créer une nation que caractérise la volonté intégratrice (voir pp. 247-251), il fallait avoir recours à des mythes fondateurs, que ce soit celui des pères pèlerins, de la liberté de conscience et de la liberté individuelle. Plus important encore aux yeux de l'auteur est le mythe de la frontière, dont on peut mesurer les causes plus facilement que les effets ; mais, au sens américain du mot, « frontier », signifie une ligne devant être franchie, car c'est à partir de là que réside le dépassement de soi comme de la communauté, ce qui l'oppose au sens anglais (ou français) de borne, de limite qui enferme. Autre mythe, créé très tôt et de toutes pièces, celui de Christophe Colomb, devenu le réfèrent emblématique de cette Amérique nouvelle, sorte de figure d'Hercule ou de ces héros mythiques d'origine troyenne dont la Rome antique ou encore la monarchie française avaient su se parer. Il est important de noter que le choix de Colomb pouvait se justifier à la fois parce que le navigateur génois était tout dévoué aux intérêts du commerce de la couronne de Castille (ce qui entre bien dans l'esprit pragmatique des Américains) et parce que le nom d'Amerigo Vespucci, florentin, avait été choisi, dès 1509, par le géographe allemand Martin Waldsemùller pour nommer le nouveau continent. En choisissant Colomb, le premier découvreur d'Hispaniola en 1492, les Américains du Nord créaient une nouvelle entité, séparée et comme différente, car placée sur une marche plus haute, du reste du continent, encore largement sous la coupe de l'Espagne. À ce combat volontariste enfin, il fallait des instruments, des journaux (le rôle de la famille de Benjamin Franklin et de sa Pennsylvania Gazette est déterminant, mais Bernard Cottret nous montre aussi l'importance des Lettres d'un fermier, parues dans le Pennsylvania Chronicle du 2 décembre 1767, sous la signature de John Dickinson) et une langue. Le Hollandais (et huguenot) John Jay s'y consacre en ces termes, dès 1787 :

5 «J'ai souvent remarqué que la Providence a souhaité accorder un territoire continu à un peuple uni ; ce peuple a reçu en partage des ancêtres communs et une langue commune; il professe les mêmes principes religieux et s'est attaché aux mêmes principes gouvernementaux, les mœurs et coutumes se ressemblent et au prix des 
efforts il a su par la volonté et la persévérance prendre les armes afin de lutter noblement jusqu'à la liberté générale et à l'indépendance. Ce pays et ce peuple semblent avoir été créés l'un pour l'autre, comme si la Providence avait voulu qu'un héritage commun fût transmis à un groupe de frères, unis entre eux par les liens les plus forts, afin que jamais il ne sombrât sous le contrôle d'une multitude de souverainetés jalouses, étrangères et agressives. »

6 Nous avons choisi de recopier in extenso cette citation parce qu'elle nous semble parfaitement poser l'un des aspects les plus fondamentaux de la civilisation américaine, de cette quête de l'unité qui doit apporter le bonheur (le slogan " unité and conquer " figure sur de nombreuses gravures de propagande des années 1750-1770). Et Noah Webster, lexicographe, défend le principe d'une américanisation de la langue anglaise car, à peuple nouveau langue nouvelle ; il participe en bonne place dans le cortège qui célèbre la ratification de la Constitution, le 23 juillet 1788, à New York. Ainsi, L'American Dictionary of the English Language intronise-t-il une simplification phonétique de la langue anglaise, et "colour, honour, humour " deviennent "color, humor, honor ", tout comme «center, theater " à la place de «centre, théâtre ». On voit ici que les modifications «américaines » de la langue en ont facilité les apprentissages pour les nouveaux immigrants, et la manipulation pour les activités économiques. Tout le pragmatisme américain rejoint le lyrisme des héros de la Révolution.

7 Clins d'œil de l'histoire : La Luzerne, ministre plénipotentiaire de France aux États-Unis écrit depuis Philadelphie, à Montmorin (alors ambassadeur de France à Madrid), que ce pays lui paraît comme sorti de « l'Ancien Régime »... ou encore, Louis XVI, jaloux de la trop grande popularité de Benjamin Franklin, offrant à la princesse de Polignac... un pot de chambre dont le fond était orné du visage du héros américain!

Pour conclure, on aura compris que cet ouvrage, tout en nous apportant un grand nombre d'informations et de réflexions politiques et philosophiques empreintes d'un humanisme généreux et enthousiaste sur le moment fondateur de l'histoire des ÉtatsUnis, rendra de grands services à tous les spécialistes de la Révolution française et des révolutions européennes du XVIII ${ }^{\mathrm{e}}$ siècle. 